\title{
The Effect of Using a Program Based on Multiple Intelligences Theory in Teaching Geometry on Developing Preparatory Stage Pupils' Habits of Mind
}

\section{Halah Mahmoud Hassan}

Assistant Lecturer at Dept of Curriculum and Instruction, Faculty of Education, Minia University, Egypt

\section{ABSTRACT}

The ability of individuals to employ intelligent behavior when they do not know the correct answer or solution to a problem is a basic skill that must be acquired through the study of geometry, and these behaviors are called the habits of mind. The application of the theory of multiple intelligences in teaching can affect the development of these habits, because they present content in ways that suit different learners' intelligences, and thus they practice a range of mental habits according to these intelligences. The aim of this research was to identify the effect of using a program in teaching Geometry based on the theory of multiple intelligences on the development of some habits of mind of second year preparatory pupils in Minya. The research sample consisted of (72) female pupils, namely two classes chosen from among the pupils of Martyr Mohammed Hamed Abdel Hakim School in Mallawi, Minya Governorate. They were divided into an experimental group $(N=36)$ and a control group $(N=36)$. The research materials included a program for teaching Geometry based on the Theory of Multiple Intelligences to teach the similarity and converse of Pythagoras Theorem unit studied in the second semester. The program included a teacher's guide and a pupil's activity book. While the instruments of measurement included a researcher-made scale for mind habits. The findings showed that there is a statistically significant difference at (0.01) between the mean scores of the experimental group and control group on the post-application of the mind habits scale in favor of the experimental group.

Keywords: Multiple Intelligence Theory - Geometry - Habits of Mind - Preparatory Stage Pupils.

\section{Introduction}

Geometry is one of the important branches of mathematics due to its relation to the ability to think, in addition to being creative in its characteristics and its components are linked to 
the reality around us. This is what Khatib (2012) pointed out that because of its importance, the Greeks set mathematics as a standard for thinking because it works to expand the mental abilities of learners. In response to the requirements of the present time, the goals of teaching mathematics were developed to include new goals that are concerned with its practical applications, such as the ability to solve problems, make decisions and gain positive attitudes towards inquiry, research and innovation.

Hence, Abbas and Al-Absi (2007) added that updating the teaching methods of mathematics with its various branches has become an urgent necessity that must be carried out by the educational systems in order to achieve a balance between the fast-changing life in the era of globalization. Among the most famous and important of these strategies are the multiple intelligences strategies that contribute significantly to the development of thinking in its various forms.

There was a traditional tendency to judge the human mind in quantitative ways and that intelligence is what is measured by the general intelligence test, as Kaplan et al. (2001) clarified that intelligence is a general potential regardless of previous knowledge. In his book "Frames of Mind" (1983), Howard Gardner rejected intelligence as one ability measured by a single test. His research led him to the discovery of multiple types of intelligence. His theory was called multiple intelligences and he continued to develop his theory.

Howard Gardner (2006) asserted that each individual possesses multiple intelligences in varying proportions, being strong in one intelligence and weak in others. These intelligence work together with one or more intelligences prevailing over the others. As a result of his research, Gardner classified these intelligences into seven as mentioned by Armstrong (2009), namely Linguistic, Logical, Mathematical, Musical, Interpersonal, 
Intrapersonal,Bodily-Kinesthetic and Visual-Spatial intelligences. In 1993, he added the naturalistic intelligence and indicated that this number may increase in the future.

Thus, the above-mentioned pointed out the importance of applying multiple intelligences in teaching to suit the capabilities of different learners and encourage them to participate effectively in the learning process. This is what Al-Shami et al. (2013) emphasized that teachers should be trained in modern methods and trends in education to be more aware of the individual differences among learners to achieve quality teaching and learning, which does not recognize the traditional view that sees intelligence as life-long.

No matter how high the individual is in his/her intelligence, this is not enough to succeed in his/her field, and he/she must behave smartly. This is what Costa and Kallick (2003) call mind habits that guide the individual throughout his/her life as each individual tends to rely on a set of these habits that are closely related to their types of intelligence. Hart (2008) mentioned that one of the main reasons for the low achievement of students in mathematics and their inability to perceive mathematical concepts is the poor level of their mind habits.

Although, there are many theoretical orientations in the classification of mind habits dimensions in accordance with the different views of specialists, the classification of Costa and Kallick is one of the most convincing classifications in explaining and interpreting them. As explained by Al-Harthy (2002), this classification depends on the findings of many studies more than the other classifications, which identified sixteen mind habits that have semi-agreed clear-cut definitions, can be learned and trained in and usually comprise a set of cognitive processes and thinking skills.

Costa and Kallick (2003) identified these habits as: persisting, managing impulsivity, listening with understanding and 
empathy, thinking flexibly, thinking about thinking, striving for accuracy, questioning and posing problems, applying past knowledge to new situations, thinking and communicating with clarity and precision, gathering data through all senses, creating, imagining and innovating, responding with wonderment and awe, thinking interdependently, taking responsible risks, remaining open to continuous learning, and finding humor.

Ricketts (2004) explained the importance of developing the habits of mind of learners. They help learners to organize their stock of knowledge, effectively manage their ideas and train them to arrange things in new ways and view them differently in order to solve problems. Developing the habits of mind in mathematics curricula is of great importance, as Kamal (2014) mentioned that they help the learner to renew, innovate, perfect the processes of thinking and refine talents in mathematics and employ them during learning, which develops positive tendencies towards studying, activates learners to practice these habits in solving mathematical problems, and improves the learning outcomes of Geometry.

Due to the importance of the habits of mind, several projects that aimed at developing and making them a community culture have been prepared by some educational institutions, universities and scientific bodies, such as the Bow Valley College Project (2001), the Adrian College Project (2002), the University of Nebraska Project (2006) and the Costa Project, Tomorrow's Learning project (2009), which emphasized the development of habits of mind to make them the general culture of members of the community. In addition, many studies concerned with the development of learners' habits of mind at different stages of education and used experimental treatments of various programs, strategies and theories of teaching, such as the studies of Bergman (2007), Venderson (2010), Fathallah (2009), Mentors et al. (2010), and Al-Banna (2012). These studies emphasized the importance of developing the habits of mind of 
both teachers and learners to become an integral part of the learning process.

\section{Research problem}

It is clear from the above-mentioned that there is a necessity for developing methods of teaching mathematics in general and Geometry in particular, that gives the learners a set of habits of mind which are necessary for them in various areas of life. This motivated the researcher to prepare a program based on the theory of multiple intelligences in teaching Geometry to measure its effect on the development of some habits of mind of second year preparatory pupils. Thus, the problem of the current research is studying the effect of using a program based on the theory of multiple intelligences in teaching Geometry on the development of habits of mind of second year preparatory pupils.

\section{Research Aims}

The current research aimed to identify:"The effect of using a program based on the theory of multiple intelligences in teaching Geometry on the development of some habits of mind of second year preparatory pupils in Minya.

\section{Research Significance}

The significance of the current research lies in the following:

- Officials in the Ministry of Education may benefit from the current research in designing programs that suit all learners with their multiple intelligences.

- This research may benefit teachers by providing a guide to help them learn how to apply the theory of multiple intelligences during teaching, which improves the learning process within the classroom.

- It may contribute to providing a suitable learning environment for all learners of different abilities, which increases their positive participation in the learning process 
through its activities to suit the different types of intelligence they possess.

- The current research provides a scale for habits of mind that may benefit researchers and those involved in the field of teaching mathematics.

- Researchers in the field of curricula and teaching methods may benefit from the suggestions for further research presented in the current research.

\section{Research Delimitations}

The current research was conducted on a sample of second year preparatory pupils at the martyr Mohammed Hamed Abdul Hakim School in Mallawi (where the researcher resides), in the academic year 2017/2018.

- The "similarity" unit was chosen from the mathematics textbook of the second-year preparatory, studied in the second semester because it contains a set of topics that pupils find difficult as indicated by the results of their achievement test, and to enrich it with a set of topics through which activities can be formulated to develop habits of mind for learners.

- The content of the proposed program was taught in light of the theory of multiple intelligences, using some teaching strategies appropriate to different types of intelligence of the research sample.

- The current research was limited to some habits of mind, namely: thinking flexibly, gathering data through all senses questioning and posing problems, applying past knowledge to new situations, thinking interdependently. These specific habits of mind were chosen because of their suitability for the abilities of the study sample (second-year preparatory pupils) and their harmony with the nature of multiple intelligences theory as well as the dependent variable (problem-solving 
skills development), which was confirmed by the results of a questionnaire administered to a panel of jury members to select the mental habits appropriate to the current research. The questionnaire included a list of the sixteen habits of mind, and a definition of each habit was formulated briefly, so that the jury members can identify the most suitable ones for the second-year preparatory pupils, and arranged them according to their importance.

\section{Definitions of research terms}

\section{Program}

Ibrahim (2009) defines it as "a methodological pedagogical means based on experimental bases aiming at developing a system of presenting information and concepts while providing appropriate activities to ensure the success of the program (page: 195)".

Shehata et al. (2003) define it as "the work to be done in order to achieve the intended objectives, and it provides the concrete basis for the completion of the work and defines the aspects of the activity to be carried out within a certain period of time."

In addition, it is a set of activities and practices held in the classroom or room of activities for a specific period of time, according to the planning and organization of a specific goal, and these activities and practices benefits all (page: 74).

In the present research, it is defined operationally as a comprehensive outline of the educational process that includes objectives, teaching aids, content and teaching strategies and methods of evaluation, which is designed in light of the theory of multiple intelligences in order to teach the unit of "similarity" assigned to second year preparatory pupils in the second semester.

\section{Multiple Intelligences}

Jaber (2003) defines them as "the practical, distinct and developmentable skills known as Howard Gardner's eight 
intelligences, namely linguistic intelligence, mathematical-logical intelligence, spatial intelligence, bodily-kinesthetic intelligence, musical intelligence, Intrapersonal intelligence, Interpersonal intelligence, and naturalistic intelligence, (Page: 9 - 10).

Gardner (1993) defines intelligence according to the theory of multiple intelligences as "the capacity to solve problems or to fashion products that are valued in one or more cultural setting, a fertile context and a natural situation". He therefore proposed eight different intelligences, namely linguistic intelligence, mathematical-logical intelligence, spatial intelligence, bodilykinesthetic intelligence, musical intelligence, intrapersonal intelligence, interpersonal intelligence, and naturalistic intelligence, (Page:35).

Teaching based on multiple intelligences is defined in the current research as a set of procedures including some teaching strategies that fit the eight intelligences proposed by Gardner, which are used to develop some of the habits of the mind the among second year preparatory pupils, namely thinking flexibly, gathering data through all senses questioning and posing problems, applying past knowledge to new situations, thinking interdependently.

\section{Habits of mind}

Costa and Kellick (2000) define them as "consistent and continuous mental performance patterns in working towards intelligent and rational behavior in order to face different life situations".

Nofal (2010) defines them as "the set of skills, attitudes and values that enable an individual to build preferences of intelligent performance or behavior based on the data to which he or she is exposed. They lead him/her to the selection of a mental process or behavior from the sum of skills available to him/her to confront a problem or issue or apply a behavior effectively and permanently, (page: 68). 


\section{In the current research, the habits of mind are}

operationally defined as a set of mental behaviors that require the use of the mind and thought, which can be used by the pupil when facing educational problems in mathematics, so he/she does some mental performances, such as thinking flexibly, gathering data through all senses questioning and posing problems, applying past knowledge to new situations, thinking interdependently. They are estimated in accordance with the scores obtained by the pupils on the scale of habits of mind which was prepared for that purpose.

\section{Theoretical Background}

\section{A - Multiple Intelligence Theory}

There are many theories that dealt with intelligence, such as the Piaget theory and psychometric theory. What these theories have in common is that they agree on that intelligence is an integrated structure and performance in one task is linked to performance in other tasks. All these theories focused on the outer side of the process of teaching and learning, and did not reach the essence of being a student and analysis of his/her actual abilities, such as intelligence, the ability to face situations and problems and find solutions to such issues. This view remained prevalent until the theory of multiple intelligences emerged.

Steenberg (2008) explains that this theory dates back to the early 1980s, when Howard Gardner refused, in his book Frames of Mind, to consider intelligence as one ability that can be measured by one test, and his experimental research led him to find multiple foundations to identify multiple types of intelligence ranged between seven and ten patterns until it ended up with the adoption of eight intelligences. Thus, Howard Gardner's theory was called the theory of multiple intelligences.

Gardner defined the concept of intelligence, as suggests by the theory of multiple intelligences, as follows: 
- The ability to produce something influential that provides valuable service in the culture.

- The possibility of finding solutions to problems that enable the production of good knowledge.

- A set of skill that enables a person to solve problems in a new way, (Page: 21).

Multiple intelligence theory asserts that each individual possesses each type of intelligence to varying degrees with the dominance of one or more intelligence over others. This is what explained by Gardner (2006) that each individual possesses multiple intelligences and is strong in some of these intelligences and weak in others. In addition, these intelligences work together in a complex way and interact with each other, (page: 32).

Al-Shami et al. (2013) also emphasized that teachers must be trained in recent methods and trends in education, in order to develop their teaching skills to be more aware of the individual differences among learners. This has become a necessary requirement imposed by contemporary reality characterized by the quality of teaching and learning, which does not recognize the traditional view of intelligence that sees it as fixed in the various stages of life, (page: 98).

Therefore, it is clear that teachers must make sure that each learner possesses eight intelligences, but in varying proportions and what he/she must do is to discover the types of strong intelligences in each learner and exploit them in providing information to him/her in a way that suits such intelligence. Thus, the teacher provides a variety of methods of teaching to meet these different intelligences of his/her learners, making learners draw, play roles, discuss, compose, sing, discover and conduct experiments and other activities. That is to say they carry out different activities in which each of them finds himself/herself and enjoys learning as he/she is the one who 
produced knowledge and did not receive it directly from the teacher.

\section{Postulates of the Theory of Multiple Intelligence}

Obeidat et al. (2007) explained that Gardner's theory was associated with basic postulates:

- There is not one fixed intelligence we inherited, and cannot be changed.

- The current intelligence tests are logical-linguistic and do not cover all the types of intelligences that exist in each individual.

- Each individual has a number of intelligences and not one intelligence.

- It is possible to develop the intelligences that we have as they are not fixed.

- Children learn if learning is suitable to the intelligences that they have.

- Each person has a profile of intelligence. This profile can be drawn for each person.

- The eight intelligences vary for each person and it is impossible to have a profile for someone that is similar to the profile of another person.

- Strong intelligence can be exploited for the development of the weak one. (page: 266)

Based on these postulates, it is clear that intelligence is a multiple set of intelligences that are capable of growth and development and each person has a unique combination of multiple intelligences. Multiple intelligences can be developed to varying degrees if the opportunity arises, besides, multiple intelligences and cognitive abilities that underlie each type can be identified and measured. Based on these postulates, the current research sought to discover the intelligences that exist in each learner, which increases his/her self-confidence, through 
his/her participation in various learning activities that suit his/her abilities and tendencies. This contributes to the development of many educational aspects, such as motivation for learning, adjusting the attitude towards the study of mathematics in general and geometry in particular, and the survival of the learning retention and thus increasing achievement, in addition to many other aspects, including what is related to the current research, such as the development of skills of solving geometric problems, some habits of mind, and the attitude towards geometry.

\section{Foundations of the theory of multiple intelligences}

Gardner described each of the seven categories of intelligence, which no one had ever thought of as intelligences, but they could have been put under the title of different abilities, thus he laid out a set of theoretical foundations for his theory, which relied on some different tests and criteria. Abdulsalam (2010) mentioned these foundations:

- The possibility of some types of intelligence to work when a brain damage occurs.

- The existence of some individuals and children with miracles.

- An intelligence can be developed through some kind of activities.

- Multiple intelligences relate to the history of Arab human civilizations.

- Tests confirm the success of Gardner's theory.

- Psychological studies confirms multiple intelligences.

- Multiple intelligences relate to designing computer programs.

- The coding system emphasizes the presence of multiple intelligences. (page: 15-24)

\section{Types of Multiple Intelligences}

Armstrong (2009) stated that, according to Howard Gardner's Multiple Intelligence Theory in 1983, multiple intelligences are categorized into seven different types available to each human 
being, but they appear in varying degrees from one person to another.These seven intelligences are namely linguistic intelligence, mathematical-logical intelligence,spatial intelligence ,bodilykinesthetic intelligence, musical intelligence, intraperson- al intelligence, interpersonal intelligence. However, Gardner in 1993 added an eighth type of intelligence, that is, naturalistic intelligence which is associated with nature or natural issues and phenomena. Gardner pointed out that this number may increase in the future, (page:3).

\section{Planning to teach using multiple intelligence theory}

Jaber (2003) explained that when applying the theory of multiple intelligences to the curriculum, it is best represented by using a different set of teaching strategies, Therefore, the best approach to the development of the curriculum is through thinking about how to translate the subject into different intelligences. The lessons and units of the curriculum can be planned using the theory of multiple intelligences following these options:

1. Focus on a specific goal or topic.

2. Ask specific key questions for each of the multiple intelligences.

3. Determine the steps and strategies used

4. Brainstorm to identify appropriate teaching strategies that can be used for each intelligence.

5 - Choose the appropriate activities for the learning situation.

6. Develop a sequential plan of the objectives to be achieved.

7. Implement the plan developed with the possibility of adjusting it to suit the changes that occur during implementation, (Page: 76-80).

\section{2- Habits of mind}

\section{Classifications of the habits of mind}

Abdulraouf (2016) explains that in their study of the habits of mind, researchers followed different approaches to the classifications of habits of mind. Daniels (1994) classified them 
into four mental habits: mental openness, mental justice, mental independence, and tendency to inquiry, and Marzano (1998) classified them into three habits: self-regulation, thoughtful thinking, and creative thinking. Moreover, Hyerle (1999) categorized them into three mental habits, each of which branches out into sub-habits: thinking maps (questioning skills, metacognitive skills, multiple sensory skills, and emotional skills), brainstorming (creativity habits, Flexibility, curiosity, expanding expertise), and organizers and drawings (persistence, organization, control, accuracy). While Gisel (2000) categorized them into ten habits: complementary thinking, connected vision, teamwork, enrichment of meaning, clarity of concepts, effective communication, courageous work, emotional care, reflective dialogue, and continuing education. Besides, Costa \& Kalick (2000) classified them into (persisting, managing impulsivity, listening with understanding and empathy, thinking flexibly, thinking about thinking, striving for accuracy, questioning and posing problems, applying past knowledge to new situations, thinking and communicating with clarity and precision, gathering data through all senses, creating, imagining and innovating, responding with wonderment and awe, thinking interdependently, taking responsible risks, remaining open to continuous learning, and finding humor, (Page: 539).

The current research adopted the classification of habits of mind presented by "Costa and Kalick ", which includes sixteen mental habits, as explained by Nofal (2010) that this classification is the most convincing classifications in explaining and interpreting the habits of mind, because it depends on the findings of studies more than many other classifications that preceded it.

\section{Importance of mind habits}

In light of the interest of some pedagogical methods in increasing the cognitive outcome and attention to the cognitive quantity of education, the habits of the mind sought further, as 
they focused on ways of searching for knowledge. They are intelligent behaviors used by the individual to produce knowledge, as he sees things in unfamiliar ways and organizes knowledge in new ways to solve problems. Thus, it is necessary to pay attention to the development of learners' habits of mind at the different educational stages. Habib (2006) therefore explains the importance of the learners' acquisition of the habits of mind in the following points:

- they allow the learner to discover how the mind works while solving problems.

- they help the learner in the organization of information, and effective management of ideas, and make him/her sees things in different ways, which helps him/her to solve problems.

- they help the learner gain the habits useful for life, and to modify the habits that are not productive.

- they train the learner in taking responsibility.

- they the learner acquire accurate planning skills. (page: 43031)

\section{Strategies for developing the habits of mind}

Bakr et al. (2011) pointed out that there is a growing interest in searching for educational strategies that manage the learners' environmental conditions and encourage them to practice thinking skills through the preparation of educational programs based on a strong theoretical empirical framework. These programs work to form a set of simple mental processes and then progress gradually to the higher and complex mental processes, resulting in processes that enable the individual to develop his/her intellectual output to become mental habits used by the individual in various areas of scientific and academic life, (Page: 297)

\section{Characteristics of mind habits}

Costa and Kalick (2000) explained that the habits of the mind have a number of characteristics as follows: 
- Evaluation: means the ability to choose and compare/contrast alternatives.

- Tendency: means the tendency to use a pattern of intellectual behaviors.

- Sensitivity: means the choice of time, place, nature of the situation and other conditions appropriate to the implementation of a behavior.

- Ability: means possessing the basic abilities and skills to implement and achieve intellectual behaviors.

- Commitment: means commitment to the development of behavior on an ongoing basis.

- Politics: means the use of rationality in all practices, decisions, actions and solutions, and making it a consistent policy that should not be skipped, (Page: 9)

\section{Research hypotheses}

Based on the findings of the previous studies, the following research hypothesis was formulated:

- There is a statistically significant difference between the mean scores of the experimental group participants (who studied the "similarity" unit using the program based on multiple intelligences theory) and control group participants (who studied the same unit in the conventional method) on the post-application of the mind habits scale in favor for the experimental group.

\section{Research Methodology}

It includes an explanation of the research procedural steps, in terms of research design, variables, sample, selection, instruments, construction and statistics. It is presented as follows:

\section{Research design}

The current research adopts the quasi-experimental design which is based on the two groups: an experimental group (taught 
using the theory of multiple intelligences) and control (studying the same content in conventional method) and comparing the performance of the two groups on the post-application of the scale of habits of mind.

\section{Research variables:}

- The independent variable (experimental) is: Teaching using a program based on the theory of multiple intelligences in the teaching of the "similarity" unit in the second semester to second year preparatory pupils (research sample).

- 2- The dependent variables are: Developing some habits of mind (thinking flexibly, gathering data through all senses questioning and posing problems, applying past knowledge to new situations, thinking interdependently) among second year preparatory pupils (research sample).

\section{Research material and instruments}

To achieve the aims of the research, the educational material included a researcher-made program prepared according to the theory of multiple intelligences to teach the geometry curriculum to the second-year preparatory pupils in the second semester. The program included a teacher's guide which included a set of lessons prepared according to the theory, and the research has followed the following steps in the preparation of the lessons of the program :

- Determining the title of the lesson.

- Determining the behavioral objectives of the lesson.

- Warming-up.

- Presenting the lesson through which the educational content was presented using the theory of multiple intelligences in the form of different educational activities, and the activities were carried out according to these steps: (Determining the objective of the activity - determining the target intelligence of the activity - determining the appropriate teaching strategy 
for such intelligence - determining the tools used in the activity - determining the steps of the activity - implementing and evaluating the activity). Homework comes at the end of each teaching period and is followed up in the next class.

The program also included a pupil's activity book whose activities were organized as follows: the title of the lesson, introductory question, the objective of the activity, the target intelligence of the activity, the tools used in the activity, the steps the pupil takes during the activity, the conclusion and evaluation to identify the extent to which the objective of the activity is achieved.

While the research measurement instruments included a scale for the habits of mind. The following steps were followed to develop the scale: identifying the objective of the scale, identifying the theoretical and methodological bases for developing the scale, determining the habits of mind to be measured by the scale and the definition of each of them (thinking flexibly, gathering data through all senses questioning and posing problems, applying past knowledge to new situations, thinking interdependently), developing the items of the scale, preparing the preliminary form of the scale, preparing of the final from of the scale, piloting the scale, conducting the statistical treatments, and setting the method of the scale scoring.

After submitting the preliminary form of the scale to the jury members and making the necessary modifications in light of their suggestions, the number of the items of the scale became (40) distributed over the five habits, namely (8) items for each mental habit. After piloting the scale and conducting the statistical treatments, the scale reliability was $(0,95)$ which is a high degree of reliability. Furthermore, the internal validity of the scale was (0.97), which is a high degree of validity. The time required to apply the scale was (35) minutes, and the scale was 
scored on the basis of choosing (always (3) - sometimes(2) never (1)). The positive items take (3-2-1), but negative items take (1-2-3), and the total score is 120 and the lowest score is 40 .

\section{Research sample}

A group of pupils chosen from among the second year preparatory at Martyr Mohammed Hamid Abdul Hakim Preparatory School in Mallawi, Minya Governorate. They were (72) pupils, namely two classes. They were divided into an experimental group $(\mathrm{N}=36)$ and a control group $(\mathrm{N}=36)$.in the school year 2018/2019

\section{Conducting the research experiment}

The implementation of the experiment began on (7-2-2018), as the scale was applied to the pupils of the research groups (experimental and control) before starting to teach the unit (similarity) according to the teaching plan at the school for all pupils. Then, the teaching process was conducted as follows:

\section{Teaching similarity unit:}

The unit of similarity was taught to the experimental group according to the theory of multiple intelligences, and the same unit was taught to the control group in the conventional way. Teaching lasted for (18) session, namely a session or a session and a half per week, and the duration of each session was 45 minutes. The research experiment ended in (19-3-2018), after that the scale was applied (post- application) to the students of the research groups, and the scale was scored, and the results were drawn.

\section{Research findings}

To answer the question: What is the effect of a program based on the theory of multiple intelligences in teaching geometry on the development of habits of mind of the second-year preparatory pupils? and to verify the hypothesis "there is a statistically significant difference between the mean scores of the experimental group and the control group pupils on the post- 
application of the mind habits scale in favor of the experimental group pupils", the mean scores of the experimental and control groups on the post-application of the mind habits scale were compared as shown in the following table:

Table (1)Mean, standard deviation, $t$-value and significance level the two research groups on post-application of the habits of mind scale

\begin{tabular}{l|c|c|c|c|c|c|c}
\hline \multicolumn{1}{c|}{ Group } & N & Mean & SD & $\begin{array}{c}\text { T- } \\
\text { Value }\end{array}$ & Sig. & $\begin{array}{c}\text { Effect } \\
\text { Size }\end{array}$ & $\begin{array}{c}\text { Sig. of } \\
\text { Effect Size }\end{array}$ \\
\hline Experimental & $\mathbf{3 6}$ & $\mathbf{1 2 7 , 8 3}$ & $\mathbf{1 0 , 0 8}$ & $\mathbf{7 , 1 5}$ & $\mathbf{0 . 0 1}$ & $\mathbf{0 . 4 2}$ & High \\
\hline Control & $\mathbf{3 6}$ & $\mathbf{1 1 , 0 6 4}$ & $\mathbf{1 0 , 3 2}$ & & & & \\
\hline
\end{tabular}

Table (1) shows that there is a statistically significant difference between the mean scores of the experimental group and the control group pupils on the post-application of the mind habits scale in favor of the experimental group pupils. The calculated t- value is $(7,15)$ at $(0.01)$ and freedom degree is $(70)$. These results confirm the positive effect of using multiple intelligence theory in teaching.

Thus, the research question was answered, and the hypothesis was accepted" The mean scores of the experimental and control groups on each dimension of the mind habits scale were compared.

Table (2) Mean, standard deviation, t-value and significance level the two research groups on each dimension of the habits of mind post-scale

\begin{tabular}{|c|c|c|c|c|c|c|c|c|}
\hline Mind Habits & Group & $\mathbf{N}$ & Mean & SD & $\begin{array}{c}\text { T- } \\
\text { Value }\end{array}$ & Sig. & $\begin{array}{l}\text { Effect } \\
\text { Size }\end{array}$ & $\begin{array}{c}\text { Sig. of } \\
\text { Effect } \\
\text { Size } \\
\end{array}$ \\
\hline \multirow{2}{*}{$\begin{array}{c}\text { Questioning and posing } \\
\text { problems }\end{array}$} & Experimental & 36 & 26.81 & 2.45 & \multirow[t]{2}{*}{6.95} & \multirow[t]{2}{*}{0.01} & \multirow[t]{2}{*}{0,41} & \multirow[t]{2}{*}{ High } \\
\hline & Control & 36 & 21.64 & 3.73 & & & & \\
\hline \multirow{2}{*}{$\begin{array}{c}\text { Gathering data through } \\
\text { all senses }\end{array}$} & Experimental & 36 & $26 ., 39$ & 2.22 & \multirow[t]{2}{*}{4.78} & \multirow[t]{2}{*}{0.01} & \multirow[t]{2}{*}{0.25} & \multirow[t]{2}{*}{ High } \\
\hline & Control & 36 & 23.28 & 3.21 & & & & \\
\hline \multirow{2}{*}{$\begin{array}{c}\text { Applying past } \\
\text { knowledge to new } \\
\text { situations } \\
\end{array}$} & Experimental & 36 & 25.06 & 3.55 & \multirow[t]{2}{*}{4.64} & \multirow[t]{2}{*}{0.01} & \multirow[t]{2}{*}{0.24} & \multirow[t]{2}{*}{ High } \\
\hline & Control & 36 & 21.44 & 3.05 & & & & \\
\hline \multirow{2}{*}{$\begin{array}{c}\text { Thinking } \\
\text { interdependently }\end{array}$} & Experimental & 36 & 24.42 & 2.48 & \multirow[t]{2}{*}{4.07} & \multirow[t]{2}{*}{0.01} & \multirow[t]{2}{*}{0.19} & \multirow[t]{2}{*}{ High } \\
\hline & Control & 36 & 21.92 & 2.73 & & & & \\
\hline \multirow[t]{2}{*}{ Thinking flexibly } & Experimental & 36 & 25.17 & 2.25 & \multirow[t]{2}{*}{3.98} & \multirow[t]{2}{*}{0.01} & \multirow[t]{2}{*}{0.18} & \multirow[t]{2}{*}{ High } \\
\hline & Control & 36 & 22.36 & 3.59 & & & & \\
\hline
\end{tabular}


It is clear from table (2) that there are statistically significant differences between the mean scores of the experimental and control groups on the post-application of the habits of mind scale at each dimension in favor of the experimental group, as t-value is significant at level (0.01). These results indicate the significant impact of the use of the theory of multiple intelligences on the development of the different dimensions of habits of mind among the pupils of the experimental group.

It is also clear from table (2) that the effect size is significant high. Ghanem (2008) indicated that the effect size that is about $1 \%$ of the total variance shows a weak effect, and the effect size that is about $6 \%$ of the total variance, which means $(0.06)$, indicates an average effect. The effect, which represents 15\% $(0.15)$ of the total variance is highly significant effect. The previous table shows that the effect size of ranges between $(0.18$, 0.41 ), which indicates a significant impact.

These findings show that the application of the theory of multiple intelligences in teaching brought about a clear improvement and succeeded in developing the habits of mind of the scale as a whole, and has a significant impact on each dimension of the scale separately, as the effect sizes of the questioning and posing problems, gathering data through all senses, applying previous knowledge to new situations, thinking about thinking, and thinking flexibly are $(0,41),(0,25),(0,24)$, $(0,19)$, and $(0,18)$ respectively.

\section{Discussion of findings}

- The outperformance of the experimental group pupils may be due to the impact of applying the theory of multiple intelligences in teaching. It enriched the topics of geometry with many activities that carry creative ideas which stimulated the thinking of the pupils. That contributed to the development of the habit of questioning that stimulates them to gather information in different ways to solve problems. 
- The use of multiple intelligences theory in teaching encouraged learners to practice many mental habits depending on the nature of each activity and in away that suits the intelligence of each learner.

- The application of the theory of multiple intelligences in teaching contributed to the development of the habit of applying previous knowledge in new situations by linking the current situations and experiences with previous experiences.

- The development of social relations between learners through collective activities helped to develop the habit of mutual thinking (collective).

- As learners practiced learning activities and being guided to seek information themselves through the activation of their previous experiences, they developed the application of previous knowledge to current situations.

- The practice of multiple intelligence activities has made learners the focus of the learning process through their active participation and the role of the teacher is limited to guidance rather than direct delivery of information.

- The effect of using multiple intelligence theory may varied from one habit to another, perhaps because these habits required longer time to be developed.

It is clear from the above-mentioned that teaching using the theory of multiple intelligences contributed significantly to the development of habits of mind among the pupils of the experimental group more than the conventional method, and the findings of the current research are consistent with the findings of the study of Al-Alimat (2013), which showed the effectiveness of the theory of multiple intelligences in the development of habits of mind of kindergarten children. In addition, there are many studies that have used various strategies to develop the habits of mind of pupils at different educational levels. 


\section{Recommendations}

In light of the findings of the present research, the following recommendations were drawn:

- The use of teaching strategies based on the theory of multiple intelligences in the teaching of geometry and other branches of mathematics in various educational stages because of their significant impact on the development of the habits of mind.

- Preparing manuals for mathematics teachers, including how to teach mathematics content using the theory of multiple intelligences.

- Paying attention to the positive role of the pupils in the learning process, giving them the opportunity to express their opinion freely, so that they can build their own knowledge, which helps them to benefit from the impact of learning.

\section{Suggestions for further research}

In the light of the findings of the current research, the following suggestions were drawn:

- The effectiveness of a program in teaching geometry based on the theory of multiple intelligences in the achievement of other objectives, such as the development of achievement and the attitude towards studying geometry.

- The effectiveness of a program in teaching mathematics based on the theory of multiple intelligences in the acquisition of mathematical thinking skills among the preparatory stage pupils.

- Conducting researches similar to the current research in different educational stages: the primary and secondary levels.

\section{References}

- Abbas, M. \& Al-Absi, M (2007). "Approaches and Methods of Teaching Mathematics at the Lower Basic Stage", Amman, Dar Al-Masirah. 
- Abdel-Raouf, M. (2016). Habits of Mind Predicting Lateral Thinking. Journal of Arab Studies in Education and Psychology, p 77, September, pp. 521-575.

- Al-Alimat, A. (2013). The impact of a program based on multiple intelligences in the development of habits of mind in kindergarten children, Journal of Childhood Studies, Vol. 16, No. 62, pp. 5498.

- Al-Banna, M. (2012). The Effectiveness of Using Thinking Maps in Developing Some Habits of Mind for Second Grade Preparatory pupils in Geometry. Journal of Mathematics Education, Vol. 15, Vol. 1, Al-Nour, pp. 43-87.

- Al-Harthy, I. (2002). "Mental habits and their development among pupils", Riyadh, Al-Shafri Library.

- Al-Khatib, M. (2012). The Effect of Teaching Geometry Using Mathematical Thinking Learning on Mathematical Theories, Proof and Applications among Tenth-Grade Students in Jordan. Journal of Educational Sciences Studies, Vol. 39, No. 1, pp. 8196.

- Al-Shami, J., Mohammed, A. \& Salem, M. (2013). Designing EActivities according to the Multiple Intelligence Theory in the Gifted Education Course and its Impact on Achievement and Motivation towards Learning among GULF Students", 3rd International Conference on E-Learning and Distance Education, 4 February 7, Riyadh, pp. 1-102.

- Armstrong , T.(2009). "Multiple Intelligences in the Classroom". Alexandria, Virginia, A.S.C.D Publishing.

- Bergman, D. (2007). "The effect of tow secondary science on teacher's habits of mind and action" , Doctoral dissertation , Iowa state university, USA.

- Bow Valley College (2001). "Learning outcomes habits of mind". ESL Literacy Network. Available on line at: http://www.esl-literacy.com.

- Costa, A. \& Kalick, P (2003)." Habits of Mind Development Series "Exploring Habits of Mind". Translated by Thahran National Schools, Saudi Arabia, Educational Book House for Publishing and Distribution.

- Costa, A. (2007). "Building a more through-full Learning community with habits of mind". Earcos administrators' conference, 3 November, Kuala Lumpur, Maylasia. 
- El-Sherbini, F. (2010). "Teaching and Learning Methods and Strategies for Developing Multiple Intelligences in PreUniversity and University Education", Cairo: The Book Center for Publishing.

- Fenderson, S. (2002). Instruction, Perception, and reflection : Trans-Forming beginning teacher's habits of mind, Doctoral dissertation, Available from ProQuest Dissertation and theses database . ( Order No. 3415992 , University of San Francisco) .

- Gardner , H. (2006) :" Multiple intelligence New Horizons," New York : Basic Books

- Gardner, H. (1993):" Multiple Intelligences: The Theory in practice". New York : Basic Books

- Ghanem, H. (2008). "Manual Educational statistics and by using SPSS". Cairo: the world of books

- Hart, H. (2008): "Practical strategies for Teaching of Thinking Boston" : Allan and Bacon

- Ibrahim, M. (2009). "Glossary of concepts and notions of education". World of books for publication and distribution.

- Jaber, G. (2003). "Multiple Intelligences and Understanding is Development and Deepening", Cairo, Dar Al Fikr Al-Arabi.

- Kamal, M. (2014). The effectiveness of a training unit in the habits of mind in the development of mathematical achievement and creative thinking and attitude towards it and mathematics among university students. Arab Studies in Education and Psychology, p 48, c 2, April, pp. 99-162.

- Kaplan, R. \& Scuzzy, D.P. (2001). Psychological testing: principles, applications, and Issues 5th ed. Belmont, CA: Wadsworth/Thomas Learning.

- Mentors, R., Magiera, M., Moger, J. (2010). Preservice teachers algebraic habits of mind", school science and mathematics, (32) 4, pp.59-65.

- Nofal, M. \& Sa'ifan, M. (2011). "Integrating thinking skills in the academic content" Amman: Dar Al-Masirah for Publishing and Distribution.

- Nofal, M. (2010). "Practical Applications in the Development of Thinking Using Habits of Mind", 2nd Ed., Amman, AlMasirah Publishing House.

- Obeidat, T. \& Al-Semaid S. (2007). The Brain, Education and Thinking", Amman, First Edition, Dar Al Fikr. 
- Richets, A (2004): " All Students can learn All Students can Succed", Alex , AVASC.

- Robert , J . \& James . C\& Elena, I . (2008) : "Applied intelligence": Boston .New York

- Said, A (2006). The Effect of Using (Analyze-Ask - Investigative) Strategy on Developing Habits of Mind of First year Secondary Students through Chemistry", Tenth Scientific Conference: Scientific Education: Challenges of Present time and Future Visions, Egyptian Association for Scientific Education, Fayed. , Ismailia, vol. 2, July 3-August 1, pp. 391-464.

- Shehata, H \& El-Naggar, Z. (2003). "Dictionary of Educational and Psychological Terminology", Cairo, Egyptian Lebanese House.

- The Adrian college habits of mind project (2002). Habits of mind : the project of Adrian college faculty in conjunction with Acc Et and Costa and kellick and habits of mind network. Available on line at: http://www.adrian.edulfaculty-tufflaccethudl resources \habitsmind.pdf

- Tomorrow's Learning LTD (2009). "Habits of mind , developing habits the next steps", 27 January, Mercure, Holland, house hotel, ( Available on line on 15\10\2014 at : http://www. grahamwatt @ habitsofmind.co.uk

- University of Nebraska-Lincold (2006). "Collection of habits of mind problems" , University of Nebraska-Lincold, math in the middle institute partnership. Available on line at: http://math. $\underline{\text { arizona.edulRetrieved }}$ 